\title{
AC 2003-1014: WAVELET TRANSFORMS ON THE LETTER N
}

John Schmeelk, Virginia Commonwealth University Qatar Branch 


\title{
Wavelet Transforms on The Letter $\mathbf{N}^{1}$
}

\author{
John Schmeelk \\ Department of Mathematical Sciences \\ Virginia Commonwealth University \\ College of Design Arts \\ Doha, Qatar
}

\begin{abstract}
This paper studies the two-dimensional wavelet transform applied to two-dimensional images. The classical technique oftentimes implements the Fourier transform. This paper offers a brief discussion regarding the comparison of the two transforms on a single alphabet, $\mathbf{N}$. It provides a comparison of the global properties present in the Fourier transform technique verses a more localized analysis when the wavelet transform is applied to the same image. The wavelet selected in this study is the derivative of the Gaussian since in some sense offers a nice comparison to the Fourier method.
\end{abstract}

\section{Introduction}

The applications of wavelet and wavelet transforms to discrete data are so plentiful that they have emerged as the most promising techniques in the past decade. For example the current research by the Federal Bureau of Investigation (FBI) in establishing an appropriate wavelet transform to be applied to its 30 million criminal fingerprints now stored in filing cabinets illustrates the application importance. The advantage will be to compress the data and accelerate the matching techniques. These topics are discussed in Strange ${ }^{44}$.

Our present implementation of the wavelet transform will be to apply it to a two dimensional image and to be able to extract critical and pertinent information. The literature on wavelet transforms in the one-dimensional case is very extensive. This is due in part to the fact that a signal captured from a piece of hardware can in many situations be obtained in a one-dimensional fashion. Images by their very nature require two or three dimensions and the literature is somewhat less available. However some research has been conducted in the multivariable cane and can be found in references $9,14,26,42$. We will use these developments extensively in our investigations whereby the transform will be implemented on an alphabet and its reflection in the following sequel. The overall procedures will entail a detailed analysis of a two-dimensional "mother" wavelet implemented within a wavelet transform on the alphabet, $\mathrm{N}$, together with a comparison to a Fourier transform. All graphics presented in this paper have been conducted on a MATLAB platform. A preliminary mathematical review is provided to reacquaint the reader with the mathematical analysis of wavelet theory in both the one and two-dimensional case.

\footnotetext{
${ }^{1}$ Funded by the Qatar Foundation, Doha, Qatar

"Proceedings of the 2003 American Society for Engineering Education Annual Conference \& Exposition Copyright (C) 2003, American Society for Engineering Education"
} 


\section{Two-dimensional Windowed Fourier Transforms.}

Let $\mathrm{f}(\mathrm{x}, \mathrm{y})$ be a function whose domain is the spatial location within an image located at coordinates, $(\mathrm{x}, \mathrm{y})$, and whose range gives the gray level intensity at the location, $(\mathrm{x}, \mathrm{y})$ where 0 corresponds to black and 255 corresponds to white. If we are interested in the frequency content of the gray levels, then the traditional method would be to apply the two-dimensional Fourier transform,

$$
\hat{f}(u, v)=\frac{1}{2 \pi} \int_{-\infty}^{\infty} \int_{-\infty}^{\infty} f(x, y) e^{-2 \pi j(u x+v y)} d x d y
$$

and then plot the frequency content, $|\hat{f}(u, v)|$.

Since a two dimensional image is contained on a bounded region, $[a, b] \times[c, d] \subset R^{2}$, the improper integral, (2.1), gives way to a finite bounded integral. As an example we consider the unit box illustrated in Figure 1 and plot its frequency content in Figure 2. We also illustrate the phase of the unit box in Figure 3. Traditionally, data of the form, $\mathrm{f}(\mathrm{x}, \mathrm{y})$ can be transformed by a windowed Fourier transform,

$$
(\hat{f w i n d o w}, g)\left(u, v: x_{1}, y_{1}\right)=\frac{1}{2 \pi} \int_{-\infty}^{\infty} \int_{-\infty}^{\infty} f(x, y) e^{-2 \pi j(u x+v y)} g\left(x-x_{1}, y-y_{1}\right) d x d y,
$$

implementing an appropriate window function, $\mathrm{g}(\mathrm{x}, \mathrm{y})$. To facilitate the calculations, oftentimes, $\mathrm{u}$, $\mathrm{v}, \mathrm{x}_{1}, \mathrm{y}_{1}$, are assigned regularly special values, $\mathrm{x}_{1}=\mathrm{nx}_{0}, \mathrm{y}_{1}=\mathrm{my}, \mathrm{u}=\mathrm{lu}_{0}$ and $\mathrm{v}=\mathrm{pv}_{0}$ where $\mathrm{m}, \mathrm{n}, \mathrm{l}$ and $\mathrm{p}$ range over the integers. The wavelet transform implementing a "mother" wavelet in some sense replaces the window function, $\mathrm{g}(\mathrm{x}, \mathrm{y})$. A window function is illustrated in Figure 4 to show the procedure with the Fourier spectrum.

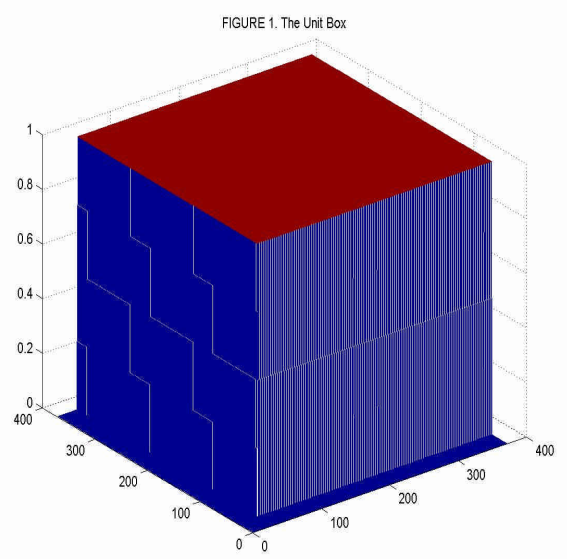



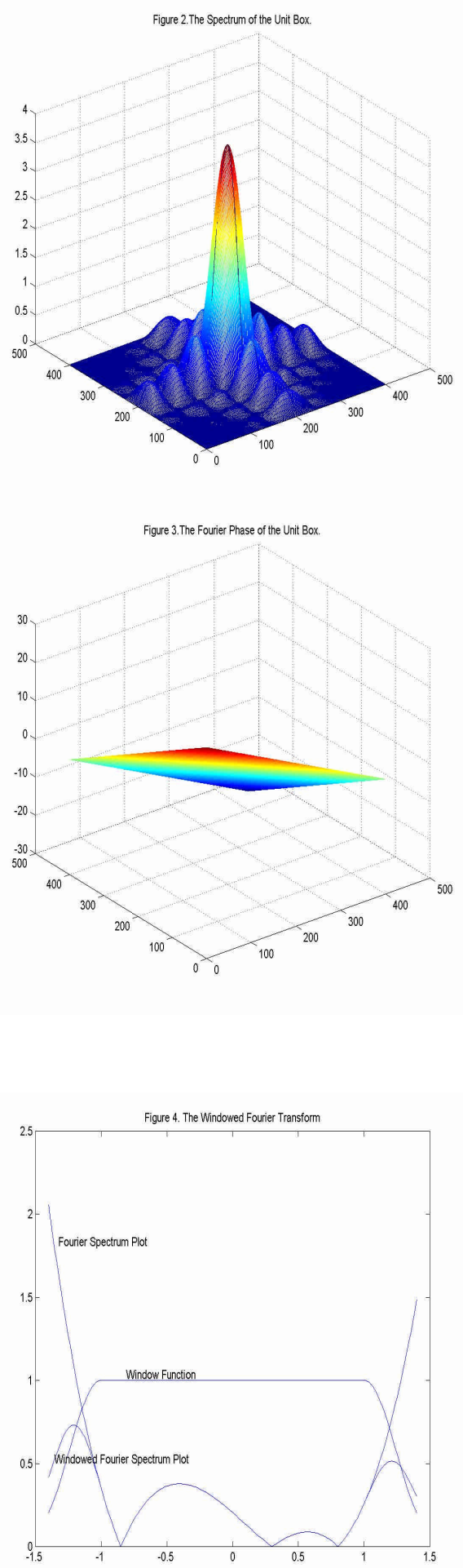

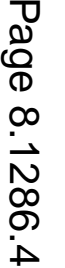

"Proceedings of the 2003 American Society for Engineering Education Annual Conference \& Exposition Copyright (C) 2003, American Society for Engineering Education" 


\section{Two Dimensional Wavelets.}

We will not include a presentation regarding multiresolution analysis leading to a scaling function and then to a "mother" wavelet. The references ${ }^{9,10,14,31,42}$ are but a few resources for this remarkable analysis.

We begin with a two-dimensional mother wavelet, $\mathrm{w}(\mathrm{x}, \mathrm{y})$, having dilation and translation parameters, $\left(a_{1}, a_{2}\right)$ and $\left(b_{1}, b_{2}\right)$ respectively each varying over $\mathrm{R}^{2}$. The dilated and translated "mother" wavelet the becomes

$$
w^{\left(a_{1}, a_{2}\right)\left(b_{1}, b_{2}\right)}(x, y)=\frac{1}{\sqrt{a_{1} a_{2}}} w\left(\frac{x-b_{1}}{a_{1}}, \frac{y-b_{2}}{a_{2}}\right)
$$

where $a_{1} \neq 0$ and $a_{2} \neq 0$. The Fourier transform of this wavelet then becomes

$$
\begin{aligned}
\mathcal{W}^{\left(a_{1}, a_{2}\right)\left(b_{1}, b_{2}\right)}(u, v) & =\frac{2 \pi}{\sqrt{a_{1} a_{2}}} \int_{-\infty-\infty}^{\infty} \int^{\infty} e^{-j \pi(u x+v y)} w\left(\frac{x-b_{1}}{a_{1}}, \frac{y-b_{2}}{a_{2}}\right) \\
& =\frac{1}{\sqrt{a_{1} a_{2}}} e^{-j \pi\left(u b_{1}+v b_{2}\right)} \mathcal{W}\left(u a_{1}, v a_{2}\right) .
\end{aligned}
$$

Furthermore Parseval's formula in $\mathrm{R}^{2}$ becomes

$$
\int_{-\infty}^{\infty} \int_{-\infty}^{\infty} f(x, y) \overline{g(x, y)} d x d y=\frac{1}{4 \pi^{2}} \int_{-\infty}^{\infty} \int_{-\infty}^{\infty} \hat{f}(u, v) \overline{\hat{g}(u, v)} d u d v
$$

Definition 3.1. The two-dimensional wavelet transform on $f(x, y)$ is then defined by the formula,

$$
\left(w^{\text {wav }} f\right)\left(\left(a_{1}, a_{2}\right),\left(b_{1}, b_{2}\right)\right)=\left(f, w^{\left(a_{1}, a_{2}\right)\left(b_{1}, b_{2}\right)}\right)=\int_{-\infty-\infty}^{\infty} \int^{\infty} \frac{1}{\sqrt{a_{1}} a_{2}} f(x, y) \overline{\left(\frac{x-b_{1}}{a_{1}}, \frac{y-b_{2}}{a_{2}}\right)} d x d y \text {. }
$$

The resolution of the identity an important inversion tool for the wavelet transform is given by the following theorem.

Theorem 3.2. For all $\mathrm{f}, \mathrm{g} \in L^{2}\left(R^{2}\right)$ there holds

$$
\left.\iiint \frac{d a_{1} d a_{2} d b_{1} d b_{2}}{\left(a_{1} a_{2}\right)^{2}}\left\{\left(T^{\text {wav }} f\right)\left(a_{1}, a_{2}\right)\left(b_{1}, b_{2}\right)\right\}\left(T^{\text {wav }} g\right)\left(a_{1}, a_{2}\right)\left(b_{1}, b_{2}\right)\right\}=C_{\varpi}(f, g) \text {. }
$$

Proof. See references ${ }^{13,14}$.

The $\mathrm{C}_{\varpi}$ in Theorem 3.2 equals 


$$
C \bar{\omega}=\iint \frac{d s_{1} d s_{2}}{\left|s_{1} s_{2}\right|} \mid \omega\left(s_{1},\left.s_{2}\right|^{2}\right.
$$

leading to the inversion formula,

$$
\mathrm{f}(\mathrm{x})=C_{\bar{\omega}}^{-1} \iiint \frac{d a_{1} d a_{2} d b_{1} d b_{2}}{\left(a_{1} a_{2}\right)^{2}}\left\{\left(T^{\text {wav }} f\right)\left(a_{1}, a_{2}\right)\left(b_{1}, b_{2}\right)\right\}\left\{\omega^{\left(a_{1}, a_{2}\right)\left(b_{1}, b_{2}\right)}\right\}
$$

Expression (3.4) requires the "mother" wavelet to satisfy the necessary condition,

$$
\iint \omega(x, y) d x d y=0
$$

IV. Wavelets in Image Processing.

A major reference for this section is the paper by S. Mallat and S. Zhong ${ }^{28}$. A smoothing function, $s(x, y) \in L^{2}\left(R^{2}\right)$, having unit length is selected and whose partial derivatives become a "mother" wavelet. The smoothing function, $\mathrm{s}(\mathrm{x}, \mathrm{y})$ has the following property proven in proposition 4.1.

Proposition 4.1 If function, $s(x, y) \in L^{2}\left(R^{2}\right)$, where $\|s(x, y)\|=1$ then all functions

$$
s_{j, k}(x, y)=2^{j / 2, j / 2} s\left(2^{j} x-k, 2^{j} y-k\right)
$$

also have unit length for all $\mathrm{j}, \mathrm{k}$ belonging to the integers, $\mathrm{N}$.

Proof. We compute the norm of $s_{j, k}(x, y)$,

$$
\left\|S_{j, k}(x, y)\right\|=\left(\iint\left(2^{j / 2} 2^{j / 2} \mid S\left(2^{j} x-k, 2^{j} y-k \mid\right)^{2} d x d y\right)^{\frac{1}{2}} .\right.
$$

Changing variables by $s_{1}=2^{j} x-k$ and $s_{2}=2^{j} y-k$ immediately gives us the result,

$$
\left(\iint\left|s\left(s_{1}, s_{2}\right)\right|^{2} d s_{1} d s_{2}\right)^{\frac{1}{2}}=1
$$

In many applications for image processing the smoothing function selected is the Gaussian function and it is illustrated in Figure 5.

We then define the two functions which become the "mother" wavelets in our image processing technique given by the partial derivatives, 


$$
\omega^{1}(x, y)=\frac{\partial}{\partial x} s(x, y)
$$

and

$$
\omega^{2}(x, y)=\frac{\partial}{\partial y} s(x, y)
$$

The dilation factors, $2^{\mathrm{j}}$, where $\mathrm{j} \in \mathrm{N}$ are then selected and the wavelet transform for $\mathrm{f}(\mathrm{x}, \mathrm{y})$ becomes

and

$$
\omega_{2^{j}}^{1} f(x, y)=f * \omega_{2^{j}}^{1}(x, y)=\iint f(\alpha, \beta) \frac{1}{2^{2 j}} \omega^{1}\left(\frac{x-\alpha}{2^{j}}, \frac{y-\beta}{2^{j}}\right) d \alpha d \beta
$$

$$
\omega_{2^{j}}^{2} f(x, y)=f * \omega_{2^{j}}^{2}(x, y)=\iint f(\alpha, \beta) \frac{1}{2^{2 j}} \omega^{2}\left(\frac{x-\alpha}{2^{j}}, \frac{y-\beta}{2^{j}}\right) d \alpha d \beta .
$$

We recall the following mathematical result for convolution.

Theorem 4.3 $D(f * g))=D f * g=f * D g$ where $D$ is a differential operator and $\mathrm{f}, \mathrm{g}$ are suitably differentiable functions.

Proof: See any mathematical reference including convolution properties for differentiable functions.

This result gives a fundamental result in image processing namely that the gradient of $\mathrm{f}(\mathrm{x}, \mathrm{y})$ smoothed by $s(x, y)$ is proportional to the wavelet transform of $f(x, y)$ in the following sense:

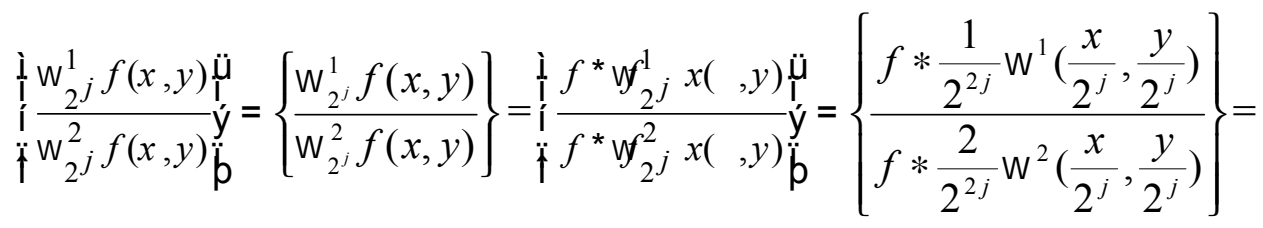

$$
\begin{aligned}
& \left\{\frac{f * \frac{1}{2^{2 j}} \frac{\partial}{\partial x} s\left(\frac{x}{2^{j}}, \frac{y}{2^{j}}\right)}{f * \frac{1}{2^{2 j}} \frac{\partial}{\partial y} s\left(\frac{x}{2^{j}}, \frac{y}{2^{j}}\right)}\right\}=\left\{\frac{f *\left(2 j \frac{\partial}{\partial x} s_{2^{j}}(x, y)\right)}{f *\left(2 j \frac{\partial}{\partial y} s_{2^{j}}(x, y)\right)}\right\}=\left\{\frac{\frac{\partial}{\partial x}\left(f * s_{2^{j}}(x, y)\right)}{\frac{\partial}{\partial y}\left(f * s_{2^{j}}(x, y)\right)}\right\}= \\
& =2^{j} \nabla\left(f * s_{2^{j}}\right)(x, y)
\end{aligned}
$$

where the gradient operator in the last equation is written in column form. For image processing the two-dimensional wavelet transform of $f(x, y)$ is the set of functions, 
$W f=\left[W_{2^{j}}^{1} f(x, y), W_{2^{j}}^{2} f(x, y)\right]$ and $\mathrm{j}$ belongs to $\mathrm{N}$.

\section{Fourier Spectrum Vs Wavelet Transform.}

The analysis of comparing the Fourier spectrum to the wavelet transform is completed on the letter, $\mathbf{N}$, which is constructed in MATHLAB and illustrated in Figure 6. The Fourier spectrum of the letter, $\mathbf{N}$, is then illustrated in Figure 7. The letter, $\mathbf{N}$, is changed somewhat for illustration purposes when one implements the wavelet transform. It is merely changing the diagonal line in the letter, N. Figures 8 and 9 illustrate the wavelet transform given by the derivatives of the Gaussian. It is completed by implementing convolution as indicated in reference ${ }^{42}$.
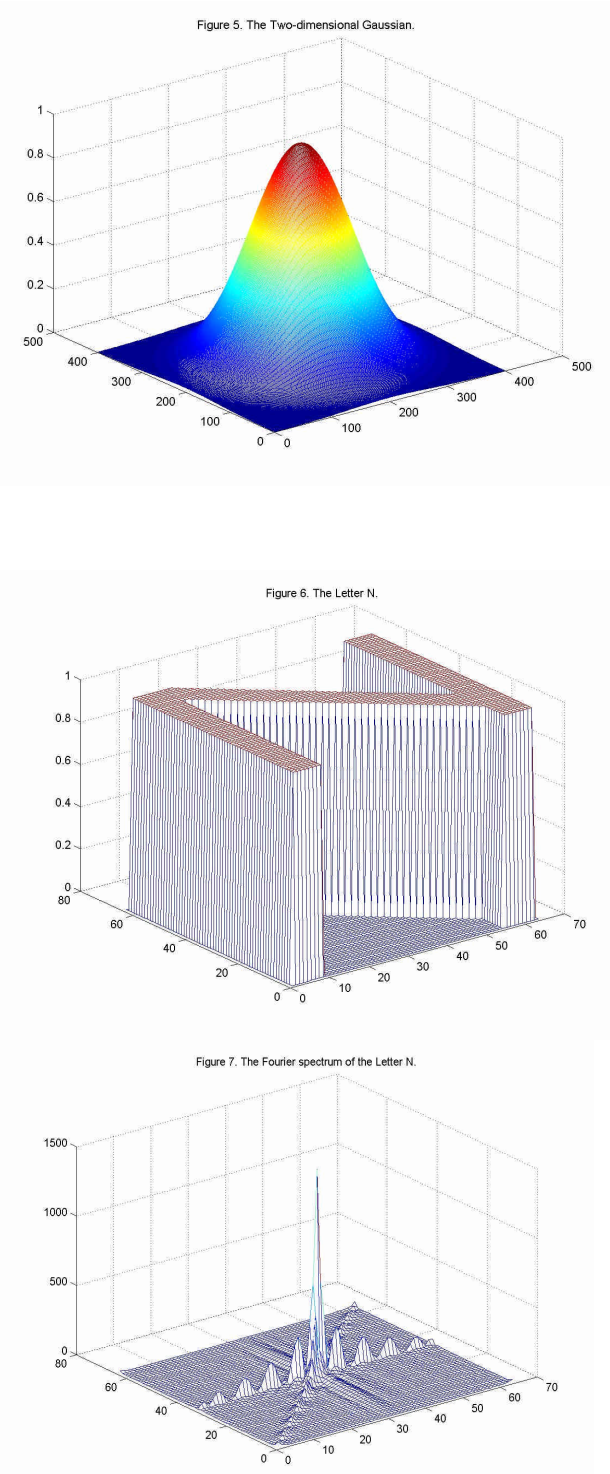


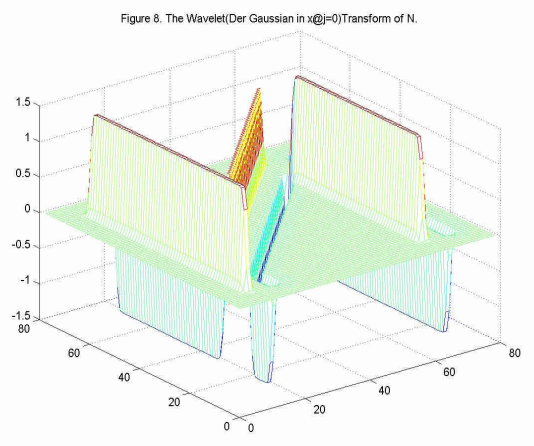

Bibliography

1. Akansu, A. \& Haddad, R. Multiresolution Signal Decomposition, Academic Press Inc., NY (1992).

2. Andrews, H. \& Hunt, B. Digital Image Restoration, Prentice Hall, NJ (1971).

3. Ballard, D. \& Brown, C. Computer Vision, Prentice Hall, NJ (1982).

4. Batchelor, B. Pattern Recognition, Plenum Press, NY (1978).

5. Bose, N. Digital Filters Theory and Applications, Elsevier Science Pub. Co. Inc. NY (1985).

6. Canny, J. Computational Approach to Edge Detection, IEEE Transactions on Pattern Analysis and Machine Intelligence, 8, No. 6, (1986), 678-698.

7. Campbell, F. \& Robson, J. Application of Fourier Analysis to the Visibility of Gratings, J. Physiol., 197, (1968), 551556.

8. Candy, J. Signal Processing-The Modern Approach, McGraw-Hill, NY, (1988).

9. Chui, C., Editor, An Introduction to Wavelets, Vol. 1, Academic Press Inc., NY(1992).

10. Chui,C., Editor, Wavelets: A Tutorial in theory and Applications, Academic Press In., NY(1992)

11. Combes, J., Grossmann, A., \& Tchamitchian, Ph., Editors, Wavelets Time-Frequency Methods and phase Space, Proceedings of the International Conference, Marseille, France, Dec. 14-18, 1987, Springer Verlag, NY (1990).

12. Daubechies, I., Time-frequency Localization Operators: A Geometric Approach, IEEE Transactions on Information Theory,32, No. 4, (1988), 605-612.

13. Daubechies, I., The Wavelet Transform, Time Frequency Localization and Signal Analysis, IEEE transactions on Information Theory, 36, No. 5, (1990), 961-1005.

14. Daubechies, I., Ten Lectures on Wavelets, society for Industrial and Applied Mathematics, PA, (1992).

15. Gader, P.D., Separable Decompositions and Approximations of Grayscale Morphological Templates, Comp. Image Understanding, 53, No. 3, (1991), 288-296.

16. Gonzalez, R. \& Woods, R. Digital Image Processing, Addison-Wesley Pub. Co., MA, (1992).

17. Haralick, R. \& Shapiro, L. Computer and Robot Vision, Addison-Wesley Pub. Co., MA, (1992).

18. Hong, Z. Algebraic Feature Extraction of Image for Recognition, Pattern Recognition, 24, No. 3, (1991),211-219.

19. Jain, A. Fundamentals of Digital Image Processing, Prentice Hall, NJ (1989).

20. Kaiser, G., An Algebraic Theory of Wavelets, I. Operational Calculus and Complex Structure, Siam J. Math. Anal., 23, No. 1, (1992), 222-243.

21. Kanal, L. Interactive pattern Analysis and Classification Systems; A Survey and Commentary, Proceedings of the IEEE, 60,(1972), 1200-1216.

22. Levy, B., Adams, m., \& Willsky, A Solution and Linear Estimation for 2-D Nearest-Neighbor Models, Proceedings of the IEEE, 78, No.4, (1990), 627-641.

23. Lim, J. Two-dimensional Signal and Image Processing, Prentice Hall, NJ, 1990.

24. Lus,S. Improving Edge Measurement on Noisy Images by Hierarchical Neural Networks, Pattern Recognition Letters, 12, (1991), 155-164.

25. Mallat, S. Multifrequency Channel Decompositions of Images and Wavelet Models, IEEE Transactions on Acoustics, Speech, and Signal Processing,37, No. 12, (1989), 2091-2110.

26. Mallat, S. A Theory for Multiresolution Signal Decomposition: The Wavelet Representation, IEEE Transactions of Pattern Analysis and Machine Intelligence, 11, No. 7, (1989), 674-693.

27. Mallat, S., Zero-Crossings of a Wavelet Transform, IEEE Transactions on Information Theory, 37, No. 4, (1991), 1019-1033.

"Proceedings of the 2003 American Society for Engineering Education Annual Conference \& Exposition Copyright (C) 2003, American Society for Engineering Education" 
28. Mallat, S. \& Zhong, S., Characterization of Signals from Multiscale Edges, IEEE Transactions on Pattern Analysis and Machine Intelligence, 14, No. 7, (1992), 710-732.

29. Marr, D. \& Hildreth, E., Theory of Edge Detection, Proc. R. Soc. London, B 207, (1980), 187-217.

30. Mersereau, R. \& Dudgeon, D. Two-dimensional Digital Filtering, Proceedings of the IEEE, 63, No.4, (1975), 610623.

31. Meyer, Y., Translated by Ryan, R., Wavelets Algorithms and Applications, Society for Industrial and Applied Mathematics, PA, 1993.

32. Nagy, G., Digital Image-Processing Activities in Remote Sensing for Earth Resources, Proceedings of the IEEE, 60, No.10, (1972), 1177-1200.

33. Ogawa, H., Symmetry Analysis of Line Drawings using the Hough Transform, Pattern Recognition Letters, 12, (1991), 9-12.

34. Oppenheim, A. \& Schafer, R., Digital Signal Processing, Prentice-Hall, NJ, (1975).

35. Pal, S. \& Ghosh, A., Index of Area Coverage of Fuzzy Image Subsets and Object Extraction, Pattern Recognition

Letters, 11, (1990), 831-841.

36. Papoulis, A., Signal Analysis, McGraw Hill Book Co., NY, 1977.

37. Pedrycz, W., Fuzzy Sets in pattern Recognition: Methodology and Methods, Pattern Recognition Letters, 23, No. 12, (1990), 121-146.

38. Poularikas, A. \& Selly, S., Signals and systems, Prindle Weber \& Schmidt, MA, 1985.

39. Pratt, W., Digital Image Processing, John Wiley \& sons, Inc. NY, 1991.

40. Ranka, S. \& Heywood, T., Two-dimensional Pattern Matching with k Mismatches, Pattern Recognition, 24, No. 2, (1991), 31-41.

41. Rosenfeld, A., Survey Image Analysis and Computer Vision, Pattern Recognition, 53, No. 3, (1991), 322-365.

42. Ruskai, M., Beylkin, G., Coifman, R., Daubechies, I., Mallat S., Meyer, Y., \& Raphael, L., Editors, Wavelets and their Applications, Jones and Bartlett, MA, 1992.

43. Schalkoff, R., Digital Image Processing and Computer Vision, John Wiley \& Sons Inc., NY, 1989.

44. Strange, G., Wavelet Transforms versus Fourier Transforms, Bulletin of the AMS, 28, No. 2, (1993), 288-305.

45. Tsai, W. \& Chou, S., Detection of Generalized Principal Axes in Rotationally Symmetric Shapes, Pattern

Recognition, 24, No. 2, (1991), 95-104.

46. Tuceryan, M. \& Chorempa, T., Relative Sensitivity of a Family of Closest-Point Graphs in Computer vision Applications, 25, No. 5, (1991), 361-373.

47. Wang, C., Huang, L., \& Rosenfield, A., Detecting Clouds and Cloud Shadows on Aerial Photographs, Pattern Recognition Letters, 12, (1991), 55-64.

48. Ziener, R., \& Tranter, W., Principles of Communications Systems, Modulation and Noise, Houghton Miffin Co., MA, 1990.

\section{JOHN SCHMEELK}

Dr. John Schmeelk is a Full Professor of mathematics at Virginia Commonwealth University in Richmond, Virginia, where he is engages in applied mathematical research in distribution theory.

He is currently teaching mathematics at VCU-Qatar College of Design Arts in Doha, Qatar. He received his BS degree in education from Seton Hall University and his MS degree in mathematics from New York University. At NYU he worked under Dr. Herbert Keller, writing his MS thesis in applied mathematics. He was a captain in the US Army Signal Corp for two years and served in Viet Nam. Dr. T.P.G. Liverman was his advisor in the area of generalized functions at George Washington University where he received his $\mathrm{PhD}$. He has spent the summers of 1986, 1988 through 1993 at Fort Rucker, Alabama where he implemented procedures utilizing generalized functions in processing discrete signals. He was invited during the summer of 1987 to contribute to an international generalized function conference held in Dubrovnik, Yugoslavia and again Varanasi, India during the winter of 1991 and again in 1998 and in the summer of 2000. Dr. Schmeelk is a member of ASEE and the AMS. 